\title{
SPONTANEOUS FORMATION OF TITANIUM NITRIDE ON THE SURFACE OF A Ti ROD INDUCED BY ELECTRO-DISCHARGE-HEAT-TREATMENT IN AN N 2 ATMOSPHERE
}

\begin{abstract}
A single pulse of 2.0 to $3.5 \mathrm{~kJ}$ of input energy from a $450 \mathrm{mF}$ capacitor was applied to a commercially pure Ti rod in a $\mathrm{N}_{2}$ atmosphere. The surface of the $\mathrm{Ti}$ rod transformed from $\mathrm{TiO}_{2}$ into titanium nitride in times as short as 159 msec, providing a bimodal morphology of the cross-section. A much higher value of hardness that was observed at the edge of the cross-section was attributed to nitrogen-induced solid-solution hardening that occurred during the electrical discharge process. The activation energy $\left(E_{a}\right)$ for the diffusion process was estimated to be approximately $86.9 \mathrm{~kJ} / \mathrm{mol}$. Results show that the electrical discharge process is a possible potential method for the nitriding of Ti; advantages include a short processing time and control of the nitrided layer without dimensional changes.
\end{abstract}

Keywords: Titanium, Surface modification, Diffusion, Heat treatment, XPS

\section{Introduction}

$\mathrm{Ti}$ and Ti-based alloys are very attractive materials for biomedical applications due to their excellent biocompatibility as well as several other outstanding properties, such as high specific strength, good fatigue properties, low modulus of elasticity and excellent corrosion resistance [1,2]. However, the practical use of these materials in biomedical applications is somewhat limited by their poor tribological properties $[3,4]$. Therefore, the surface treatments of Ti and Ti-based alloys have been intensively studied and widely reported in order to improve their surface characteristics. These cover a wide range of techniques, such as spraying, plating, chemical conversion coating, physical vapor deposition, laser surface modification, etc. [5-7], each with its own merits and limitations.

Among them, nitriding processes based on the thermodiffusion mechanism have been frequently used to form titanium nitrides on the Ti surface. Titanium nitrides have excellent corrosion and wear resistance properties as well as bioactivity, and are thus widely employed as coating materials to improve tribological performance $[8,9]$. Conventional nitriding processes have several disadvantages, however, such as long processing times, poor surface finish, poor control of the nitrided layer formation etc. [10,11].

Plasma nitriding techniques have also several problems, such as the formation of an arc which can damage the nitriding surface. In addition, a comparatively high operating pressure can increase the possibility of surface contamination and also retard the diffusion of nitrogen [11-13], which produces a very thin nitrided layer $(0.1-0.2 \mu \mathrm{m})$ even after a long treatment time. This is neither economical nor favorable for biomedical applications $[11,13]$. Recently, laser nitriding has been viewed as attractive in comparison to other nitriding processes due to its short treatment time and accuracy in controlling the treatment location. However, it involves surface melting of the substrate, resulting in dimensional changes and also in a roughened surface after nitriding.

To overcome some of these problems related to the prescribed nitriding processes, the electrical discharge technique, which uses a high voltage, high current pulse, was introduced in this study as a new nitriding process. The microstructures, hardness and surface chemistries of Ti rods in a $\mathrm{N}_{2}$ atmosphere subjected to an electrical discharge process were investigated.

\section{Experimental}

The commercial pure Ti rod (Grade 2) with a diameter of $3 \mathrm{~mm}$ and a length of $10 \mathrm{~cm}$ was ultrasonically cleaned and dried, and connected to the upper and lower tungsten electrodes. The discharge chamber was evacuated to $2 \times 10^{-3}$ torr and then filled with $\mathrm{N}_{2}$ gas at 1000 torr. The capacitor bank of $450 \mu \mathrm{F}$ was charged with four different electrical input energies (2.0, $2.5,3.0$, and $3.5 \mathrm{~kJ}$ ). The charged capacitor bank instantane-

\footnotetext{
* SEJONG UNIVERSITY, FACULTY OF NANOTECHNOLOGY AND ADVANCED MATERIALS ENGINEERING, SEOUL 05000, KOREA

** WONKWANG HEALTH SCIENCE UNIVERSITY, DEPARTMENT OF DENTAL LABORATORY, IKSAN 54538, KOREA

*** UIDUK UNIVERSITY, DIVISION OF GREEN ENERGY ENGINEERING, KYEONGJU 38004, KOREA

**** KOREA AEROSPACE UNIVERSITY, DEPARTMENT OF MATERIALS ENGINEERING, GOYANG-SI 10510, KOREA

\# Corresponding author: sychang@kau.ac.kr
} 
ously discharged through the Ti rod by turning on an on/off high vacuum switch to close the discharge circuit. The voltage and current that the Ti rod experienced when the circuit was closed were simultaneously picked up by a high voltage probe and a high current probe, respectively. Outputs from these probes were fed into a high speed oscilloscope that stored them as a function of discharge time. The overall process is referred to as electrical discharge process.

The microstructures of as-received and electrical discharged Ti rods were examined with an optical microscope (OM) and a scanning electron microscope (SEM). To determine if any change had occurred during the electrical discharge, microhardness was measured on the cross section of Ti rod with a load of $50 \mathrm{~g}$ and a dwell time of 20 seconds. The electrical discharged Ti rod without any surface treatment was subjected to X-ray photoelectron spectroscopy (XPS) to measure the elemental compositions.

\section{Results and discussion}

A typical discharge curve (Fig. 1a) shows voltage and current in terms of discharge time. $450 \mu \mathrm{F}$ in capacitance and $3.94 \mathrm{kV}$ in input voltage were employed to yield $3.5 \mathrm{~kJ}$. The input energy (E) was pre-determined by controlling input voltage $(V)$ according to the equation:

$$
E=C V^{2} / 2
$$

where $C$ is the capacitance of the capacitor. Figure 1(a) shows that the peak current was $35.2 \mathrm{kA}$ and the peak voltage was $3.2 \mathrm{kV}$. From the results shown in (Fig. 1a), the power (watt) curve is plotted in (Fig. 1b) against the discharge time. The power was obtained from the following equation:

$$
P(\text { watt })=\text { current }(\mathrm{A}) \times \text { voltage }(\mathrm{V})=I^{2} R(\mathrm{~J} / \mathrm{s})
$$

The power increases with an increase of input energy at same capacitance. The discharge times for the duration of the first cycle at four different input energies were identical to be approximately $159 \mu \mathrm{sec}[14,15]$. The amount of heat generated $(\Delta H)$ during an electrical discharge was obtained by using Eq. 3:

$$
\Delta H=S\left[i^{2}(t) R(t) \Delta t\right]
$$

Typical discharge characteristics under current conditions are listed in Table 1 in terms of peak current, peak voltage, discharge time, and $\Delta H$. It can be seen that $\Delta H$ increases with an increase of input energy at constant capacitance.

TABLE 1

Peak voltage, peak current, discharge time, $\Delta H$, and $\Delta T$ during electrical discharge processes with various input energies

\begin{tabular}{|c|c|c|c|c|c|}
\hline \hline $\begin{array}{c}\text { Input } \\
\text { energy } \\
(\mathbf{k J})\end{array}$ & $\begin{array}{c}\text { Peak } \\
\text { voltage } \\
(\mathbf{k V})\end{array}$ & $\begin{array}{c}\text { Peak } \\
\text { current } \\
(\mathbf{k A})\end{array}$ & $\begin{array}{c}\text { Discharge } \\
\text { time } \\
(\boldsymbol{\mu} \mathbf{s e c})\end{array}$ & $\begin{array}{c}\text { Heat } \\
\text { generated } \\
(\mathbf{J})\end{array}$ & $\begin{array}{c}\Delta \boldsymbol{\Delta T} \\
\left({ }^{\circ} \mathbf{C}\right)\end{array}$ \\
\hline 2.0 & 1.8 & 19.2 & 159 & 1383 & 543 \\
\hline 2.5 & 2.4 & 24.4 & 159 & 2248 & 1066 \\
\hline 3.0 & 2.6 & 29.2 & 159 & 3307 & 1707 \\
\hline 3.5 & 3.2 & 35.2 & 159 & 4695 & 2546 \\
\hline
\end{tabular}

Figure 2 shows cross-sectional micrographs of the $\mathrm{Ti}$ rods which were electrical discharged with four different input energies. No significant microstructural change after electrical discharging with an input energy less than $2.5 \mathrm{~kJ}$ occurred and no phase transformation has occurred. On the other hand, electrical discharging with $3.0 \mathrm{~kJ}$ or greater significantly caused a $\beta \rightarrow \alpha$ allotropic transformation, exhibiting a typical serrated morphology. The microstructure is very similar to that of the Ti which was annealed at $1000^{\circ} \mathrm{C}$ for 2 hours and air cooled [16]. This result implies that a temperature range extending over the $\beta$ transus was generated by the electrical discharge at input energies of $3.0 \mathrm{~kJ}$ or higher. In particular, the morphology in the vicinity of edge exhibits directional acicular microstructure of $\alpha$ phase toward the center of cross-section. This can be attributed to the diffusion of nitrogen into the Ti surface during an electrical discharge. A typical SEM and elemental Ti and $\mathrm{N}$ mapping (a)

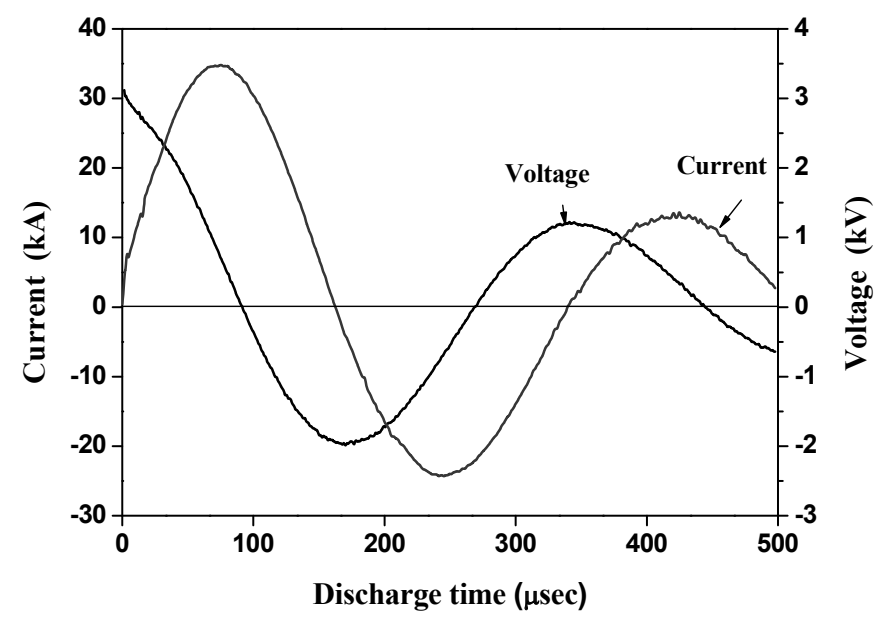

(b)

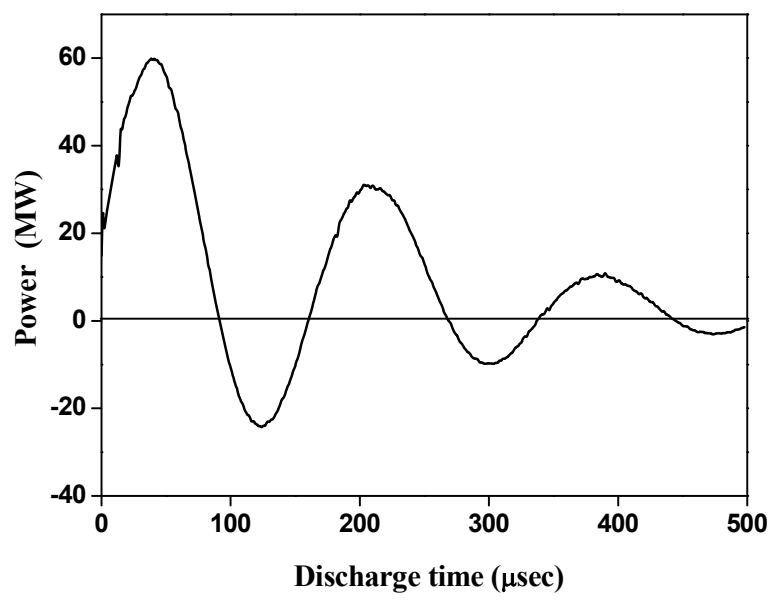

Fig. 1. (a) Typical discharge curve oscilloscope measured current and voltage, and (b) power curve versus discharge time (discharge condition: $3.5 \mathrm{~kJ}$ of input energy) 
(a)

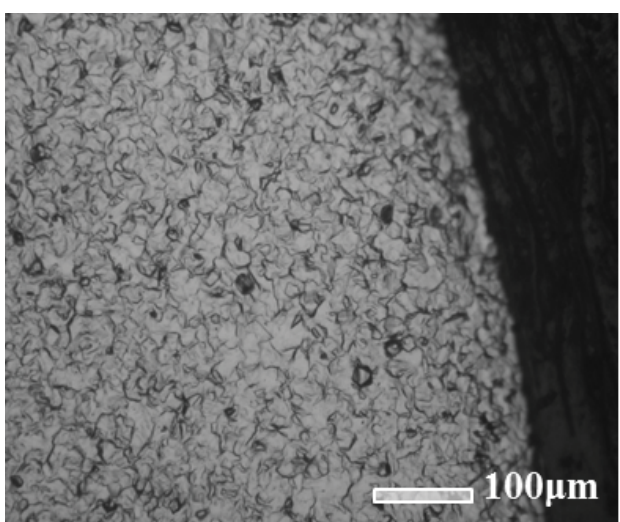

(c)

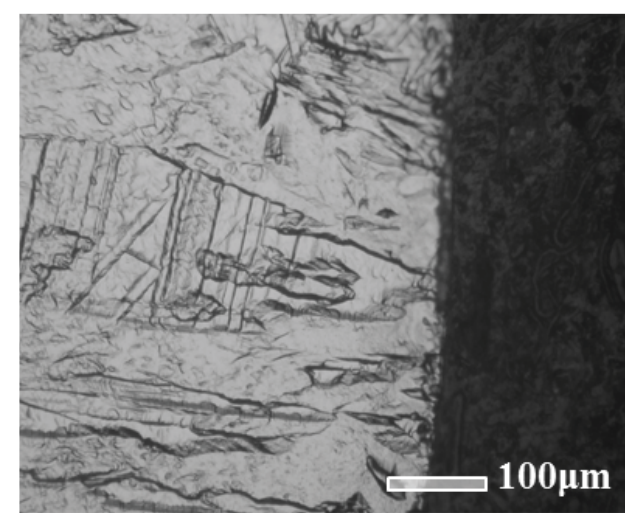

(b)

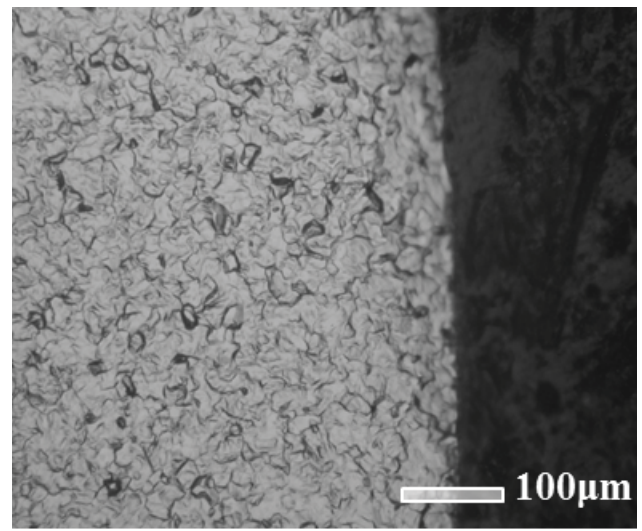

(d)

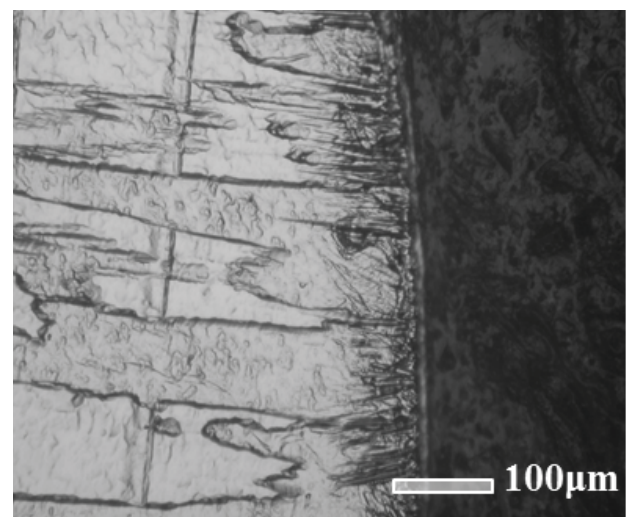

Fig. 2. Optical micrographs near to the edge of Ti rods obtained after the electrical discharge with input energies of (a) 2.0, (b) 2.5, (c) 3.0 and (d) $3.5 \mathrm{~kJ}$

(a)

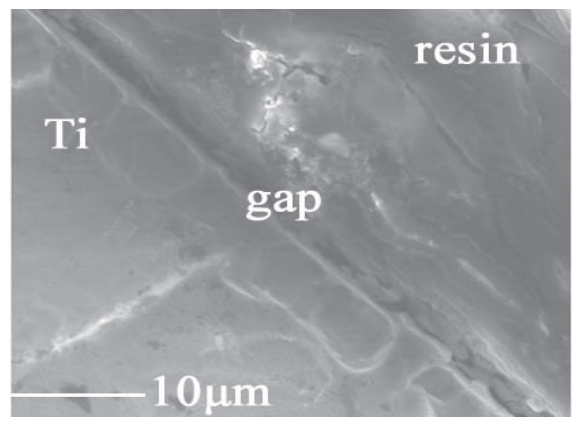

(b)

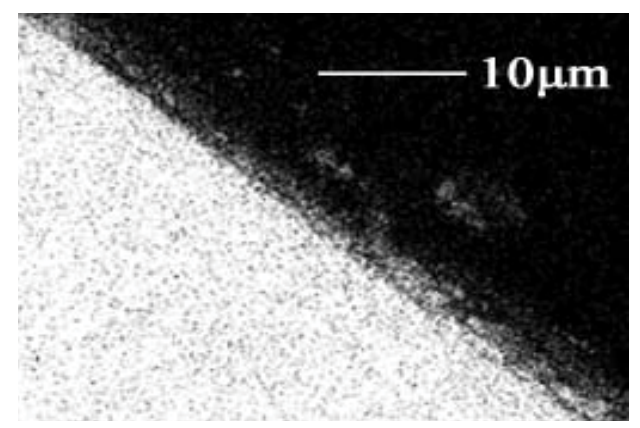

(c)

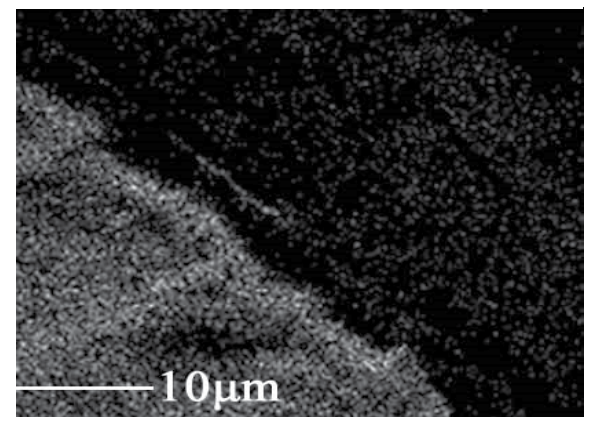

Fig. 3. (a) SEM and elemental (b) Ti and (c) N mapping micrographs on the edge of the cross-section of Ti rod which was electrical discharged at $3.5 \mathrm{~kJ}$ of input energy

micrographs on the edge of the cross-section of Ti rod which was electrical discharged with $3.5 \mathrm{~kJ}$, are shown in (Fig. 3). It is clearly seen that nitrogen diffused into the Ti surface (Fig. 3c), producing a titanium nitride layer.

Figure 4 a shows narrow scan spectra of the $\mathrm{Ti} 2 \mathrm{p}$ region for the Ti rod before and after electrical discharging with $3.5 \mathrm{~kJ}$ of input energy. The as-received Ti rod showed a Ti $2 \mathrm{p}_{3 / 2}$ peak at $458.5 \mathrm{eV}$, with $5.8 \mathrm{eV}$ splitting between the Ti $2 \mathrm{p}_{1 / 2}$ and $\mathrm{Ti} 2 \mathrm{p}_{3 / 2}$ peaks. Previous Ti narrow scan spectra results for wrought $\mathrm{Ti}$ and Ti alloys show the Ti $2 \mathrm{p}_{3 / 2}$ peak at about $459.2 \mathrm{eV}$ with $5.8 \mathrm{eV}$ splitting between the Ti $2 \mathrm{p}_{1 / 2}$ and $\mathrm{Ti} 2 \mathrm{p}_{3 / 2}$ peaks. For $\mathrm{Ti}^{4+}$, as in
$\mathrm{TiO}_{2}$, the Ti $2 \mathrm{p}_{3 / 2}$ peak is at about $459.1 \mathrm{eV}$ [17]. Peak shifts for $\mathrm{Ti}^{3+}\left(\mathrm{Ti}_{2} \mathrm{O}_{3}\right), \mathrm{Ti}^{2+}(\mathrm{TiO})$, and $\mathrm{Ti}$ (metal) are approximately -1.7 , -3.5 and $-5.2 \mathrm{eV}$, respectively $[18,19]$. Thus, the surface of the as-received $\mathrm{Ti}$ rod before electrical discharging is primarily in the form of $\mathrm{TiO}_{2}$. However, the surface of the Ti rod after electrical discharging showed a Ti $2 \mathrm{p}_{3 / 2}$ peak at $454.6 \mathrm{eV}$. Therefore, this surface is primarily in the form of TiN [20]. Figure $4 \mathrm{~b}$ shows high resolution spectra of the $\mathrm{N} 1 \mathrm{~s}$ region for the Ti rod after electrical discharging with 3.0 and $3.5 \mathrm{~kJ}$ of input energy. The maxima at $396.7 \mathrm{eV}$ are identical to the $\mathrm{N} 1 \mathrm{~s}$ peak positions for titanium nitride. This indicates the presence of a significant amount of 
(a)

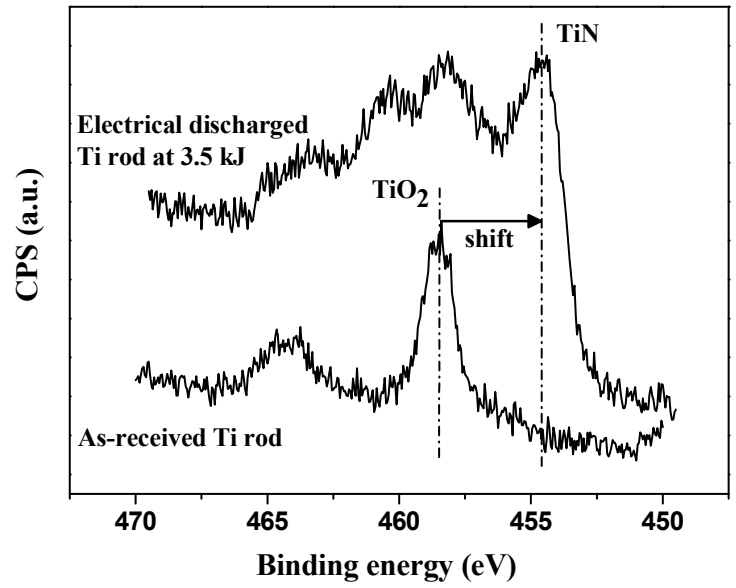

(b)

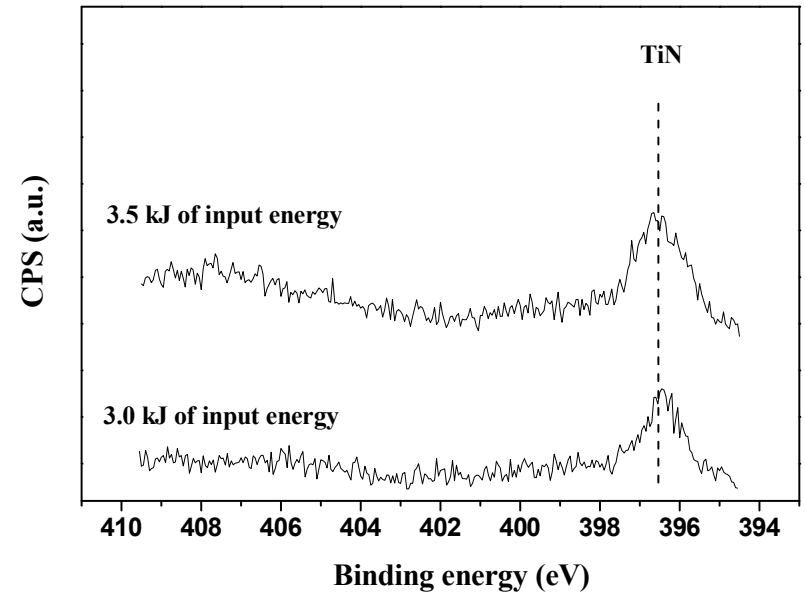

Fig. 4. (a) Ti 2p narrow scan XPS spectra of Ti rods before and after electrical discharge at $3.5 \mathrm{~kJ}$ of input energy and (b) N 1s narrow scan XPS spectra of Ti rods which were electrical discharged at 3.0 and $3.5 \mathrm{~kJ}$ of input energy

nitride and supports assignment of the titanium nitride peak to the Ti $2 p$ spectrum in Fig. 5a. Therefore, the rapid and spontaneous formation of titanium nitride on the surface of Ti rod after an electrical discharge can explain the bimodal microstructure on the cross-section. This can be why hardness, especially near to the edge, is much higher after an electrical discharge.

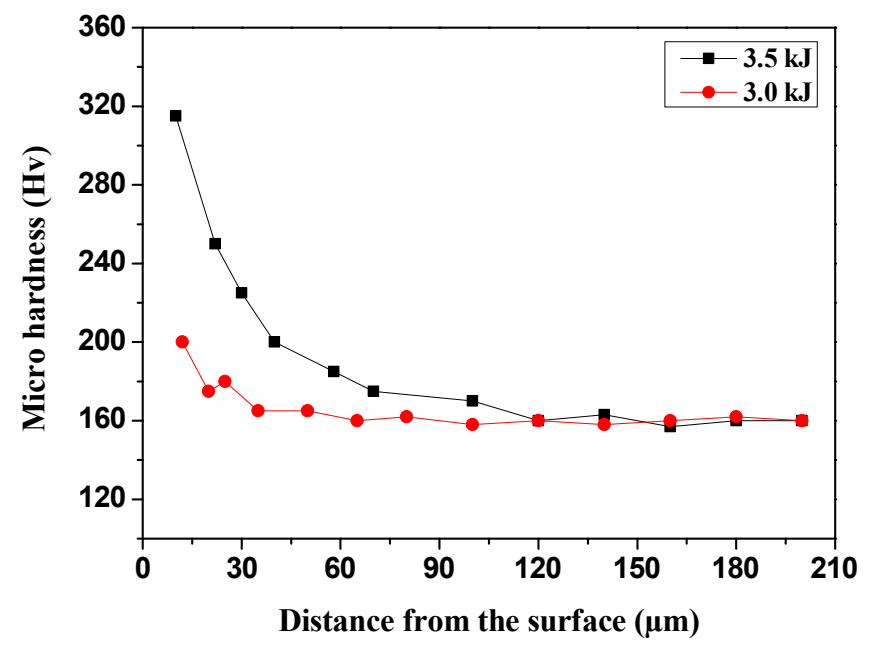

Fig. 5. Typical microhardness profiles of electrical discharged Ti rods at 3.0 and $3.5 \mathrm{~kJ}$ of input energy.

Since grain growth of $\alpha, \beta \rightarrow \alpha$ allotropic transformation, and diffusion of nitrogen during electrical discharging depend on the input energy, heat-generation will be one of the required parameters for those to be occurred. A sudden increase in temperature $(\Delta T)$ through the Ti rod, which is caused by input energy during the electrical discharge process, is now considered and estimated using Eq. 4 :

$$
W=m C_{p} \Delta T
$$

where $\mathrm{m}$ is the mass of the Ti and $C_{p}$ is the specific heat of $\mathrm{Ti}$ [21]. The electrical input power $(W)$ was calculated by integrating current and voltage as a function of discharge time. The resulting temperature increase data for the electrical discharge process under the current conditions are also listed in Table 1. It can be seen that the electrical discharge process can produce temperature increases ranging from $543^{\circ} \mathrm{C}$ to $2546^{\circ} \mathrm{C}$, depending on the input energy. The instant heat-generation $\left(543-1066^{\circ} \mathrm{C}\right)$ by the electrical discharge at 2.0 and $2.5 \mathrm{~kJ}$ of input energy caused a slight increase in grain size of the Ti rod without any phase transformation as shown in (Fig. 2a,b). On the other hand, the electrical discharge process using more than $3.0 \mathrm{~kJ}$ of input energy produced temperatures much greater than the $\mathrm{Ti} \beta$-transus temperature, resulting in a $\beta \rightarrow \alpha$ allotropic transformation even with times as short as $159 \mu \mathrm{sec}$. Moreover, the heat-generation is believed to be high enough for nitrogen to penetrate into the Ti surface, producing a titanium nitride layer.

The diffusion kinetics of nitrogen into the Ti rod during the electrical discharge process can be analyzed by using Eq. 5 :

$$
x \fallingdotseq(D t)^{1 / 2}
$$

where $x$ is the thickness of diffusion layer, $D$ is the diffusion coefficient, and $t$ is the diffusion time [22]. The diffusion coefficient at each electrical discharge condition is estimated using the microhardness profiles shown in Fig. 5, and listed in Table 2. With the increase of the input energy, the diffusion is highly activated and the nitride formation and nitrogen concentration are accelerated, which results in an increase of the hardness and growth of the diffusion layer. Formation of titanium nitride can be attributed to the high heat generated in the Ti during an electro discharge process, causing reaction between $\mathrm{Ti}$ and $\mathrm{N}$. A much higher value of hardness that was observed at the edge of the cross-section was thus attributed to nitrogen-induced solid-solution hardening. The activation energy for the diffusion process was estimated to be $86.9 \mathrm{~kJ} / \mathrm{mol}$ obtained from the Arrhenius plot of $\ln (D)$ versus $\mathrm{T}^{-1}$. This value is much lower than the values (149-170 $\mathrm{kJ} \mathrm{mol}^{-1}$ ) reported in the literature [23]. This result indicates that the electro discharge process for the surface modification of Ti can decrease the activation energy for the interstitial diffusion process. 
TABLE 2

Thickness of diffusion layer and diffusion coefficient (D) of nitrogen in Ti during electrical discharge processes with various input energies

\begin{tabular}{|c|c|c|}
\hline \hline $\begin{array}{c}\text { Input Energy } \\
(\mathbf{k J})\end{array}$ & $\begin{array}{c}\text { Thickness of diffusion layer } \\
(\boldsymbol{\mu m})\end{array}$ & $\begin{array}{c}\mathbf{D} \\
\left(\mathbf{m}^{\mathbf{2}} / \mathbf{s}\right)\end{array}$ \\
\hline 2.0 & 1.1 & $6.3 \times 10^{-9}$ \\
\hline 2.5 & 6.2 & $2.3 \times 10^{-7}$ \\
\hline 3.0 & 31.1 & $6.0 \times 10^{-6}$ \\
\hline 3.5 & 95.6 & $5.7 \times 10^{-5}$ \\
\hline
\end{tabular}

Based on the above results, eventually, the electrical discharge process can efficiently modify the Ti surface by the rapid and spontaneous formation of titanium nitride layer in times as short as $159 \mu \mathrm{sec}$.

\section{Conclusions}

Ti rods were subjected to an electrical discharge at 2.0-3.5 kJ of input energy in a $\mathrm{N}_{2}$ atmosphere using a $450 \mu \mathrm{F}$ capacitor bank. Instant temperature increases of $\mathrm{Ti}$ in times as short as 159 msec during the electrical discharge are high enough to allow nitrogen penetration at the Ti surface, producing a titanium nitride surface layer. A much higher hardness near to the surface can thus be solid-solution hardening. The activation energy for the diffusion process was estimated to be significantly low value of $86.9 \mathrm{~kJ} / \mathrm{mol}$.

The electrical discharge technique for the surface modification of $\mathrm{Ti}$ is believed to be more efficient in terms of process time and provides a simple, easy method compared to other more conventional nitriding processes.

\section{REFERENCES}

[1] V.S. Saji, H.C. Choe, Met. Mater. Int. 17, 275 (2011).

[2] F. Petzoldt, V. Friederici, P. Imgrund, C. Aumund-Kopp, J. Korea Powder Metall. Inst. 21, 1 (2014).
[3] M.G. Kim, Met. Mater. Int. 17, 705 (2011).

[4] V.K. Balla, A. Bhat, S. Bose, A. Bandyopadhyay, J. Mech. Behav. Biomed. Mater. 6, 9 (2012).

[5] F.J.C. Braga, R.F.C. Marques, E.A. Filho, A.C. Guastaldi, Appl. Surf. Sci. 253, 9203 (2007).

[6] H.C. Man, M. Bai, F.T. Cheng, Appl. Surf. Sci. 258, 436 (2011).

[7] S.Y. Kwak, H.G. Kim, J.M. Byun, J.H. Park, M.J. Suk, S.T. Oh, Y.D. Kim, J. Korea Powder Metall. Inst. 21, 28 (2014).

[8] S. Sathish, M. Geetha, S.T. Aruna, N. Balaji, K.S. Rajam, R. Asokamani, Wear 271, 934 (2011).

[9] B. Deng, Y. Tao, D. Guo, App. Surf. Sci. 258, 9080 (2012).

[10] S. Gokul Lakshami, D. Arivuoli, B. Ganguli, Mater. Chem. Phys. 76, 187 (2002).

[11] M. Rahman, I. Reid, P. Duggan, D. Dowling, G. Hughes, M.S.J. Hashmi, Surf. Coat. Technol. 210, 4865 (2007).

[12] L. Thair, U. Kamachi Mudali, R. Asokamani, Baldev Raj, Surf. Eng. 20, 11 (2004).

[13] R. Wei, T. Booker, C. Rincon, J. Arps, Surf. Coat. Technol. 186, 305 (2004).

[14 W.H. Lee, Y.J. Jo, Y.H. Kim, Y.H. Jo, J.G. Seong, C.J. Van Tyne, S.Y. Chang, Arch. Metall. Mater. 60, 1185 (2015).

[15] Y.J. Jo, Y.H. Kim, Y.H. Jo, J.G. Seong, S.Y. Chang, P.J. Reucroft, S.B. Kim, W.H. Lee, Metals Mater. Int. 21, 337 (2105).

[16] S.K. Kim, J.K. Park, Metall. Mater. Trans. A 33A, 1051 (2002).

[17] Y.J. Jo, Y.H. Kim, Y.H. Jo, J.G. Seong, Y.K. Ko, S.B. Kim, S.Y. Chang, W.H. Lee, Metals Mater. Int. 21, 159 (2105).

[18] Y.J. Jo, Y.H. Jo, J.G. Seong, Y.H. Kim, S.Y. Chang, M.S. Noh, H.G. Jeong, W.H. Lee, Surf. Eng. 31, 885 (2015).

[19] Y.J. Jo, Y.H. Jo, J.G. Seong, Y.H. Kim, S.Y. Chang, W.H. Lee, Mater. Sci. Technol. 31, 989 (2015).

[20] Y.J. Jo, Y.H. Kim, Y.H. Jo, J.G. Seong, S.Y. Chang, C.J. Van Tyne, W.H. Lee, J. Nanosci. Nanotechnol. 14, 8429 (2014).

[21] D.K. Kim, H.R. Pak, K. Okazaki, Mater. Sci. Eng. A 104, 191 (1988).

[22] D.A. Porter, K.E. Easterling, M.Y. Sherif, Phase transformation in Metals and Alloys, CRC Press, London, 1992.

[23] F. M. Guclu, H. Cimenoglu, E. S. Kayali, Mater. Sci. Eng. C 26, 1367 (2006) 